\title{
KEANEKARAGAMAN NEMATODA DALAM TANAH PADA BERBAGAI TIPE TATAGUNA LAHAN DI ASB-BENCHMARK AREA WAY KANAN
}

\author{
I Gede Swibawa ${ }^{1}$
}

\begin{abstract}
The soil nematode diversity in several land-use types in Way Kanan ASB-Benchmark Area. The conversion of forest to intensive agroecosystem such as monoculture system reduces biodiversity of the plant, herbivore, and decomposer subsystems. Those changes affected the litter and plant root quality. Consequently, few soil nematode species could be dominant and cause of disturbance of the stability of the below ground community. The increasing populations of plant parasitic nematodes usually occur on monoculture system . The research was conducted to study the effect of forest changes in several land use types on soil nematode diversity in Way Kanan Benchmark Area. Soil sampling on five land use types (secondary forest, agroforest or tree based agriculture, plantation, cassava field, and Imperata grass land) was conducted in November1996 and December 1997. Nematodes were extracted by decantation-centrifugation with sugar method. The soil nematodes were grouped into order and generic level including plant parasitic and non- parasitic. The results show that the order of Rhabditida, Dorylaimida, and Tylenchida were found from those five land-use types. The total genera of plant parasitic nematodes in Imperata grass land were the highest among the other four land use types. The total number of non-plant parasitic nematodes in secondary forest (28.0 individual per $300 \mathrm{cc}$ of soil) was higher than total number in the plantation ( 2.6 individual per $300 \mathrm{cc}$ of soil), cassava field (4.0 individual per $300 \mathrm{cc}$ of soil) or Imperata grass land (6.6 individual per 300 cc of soil). The total number of plant parasitic nematodes in Imperata grass land (59.8 individual per 300 cc of soil), agroforest (59.0 individual per 300 cc of soil), secondary forest (48.2 individual per 300 cc of soil), and plantation (17.6 individual per $300 \mathrm{cc}$ of soil) were not significantly different, but total number in Imperata grass land and agroforest were significantly higher than that in cassava field (11,6 individual per 300 cc of soil).
\end{abstract}

Key Word: diversity, nematodes, land use types

\section{PENDAHULUAN}

Belakangan ini perubahan hutan menjadi bentuk-bentuk penggunaan lahan lainnya di Indonesia sangat pesat. Hal ini terjadi akibat pertambahan jumlah penduduk dan alasan ekonomi. Hutan diubah menjadi lahan pertanian monokultur yang intensif dengan berbagai jenis tanaman semusim. Apabila telah tidak produktif lagi, umumnya lahan tersebut ditinggalkan sehingga menjadi hamparan padang ilalang. Way Kanan memiliki situs berbagai tipe tata guna lahan yang menggambarkan berbagai bentuk perubahan hutan. Di daerah tersebut dapat ditemukan adanya hutan sekunder, pertanian berbasis pohon (wanatani), perkebunan, ladang ubi kayu, dan hamparan padang ilalang.

Menurut Giller et al. (1997), perubahan hutan menjadi lahan pertanian intensif akan berdampak kepada keanekaragaman dan fungsi ekosistem tersebut. Pengelolaan pertanian yang intensif akan menurunkan keanekaragaman tumbuhan, hewan dan mikroba (Swift \& Anderson, 1994). Tumbuhan di atas permukaan tanah mempengaruhi organisme di dalam tanah melalui kualitas seresah, eksudat akar, dan iklim mikro (van Noordwijk \& Swift, 1999).

Selama ini, nematoda dipandang penting oleh manusia karena perannya sebagai organisme pengganggu tanaman yang dapat menurunkan produksi. Nematoda yang dimaksud adalah nematoda parasit tumbuhan. Nematoda ini merusak sistem perakaran tumbuhan. Populasi nematoda dipengaruhi oleh ketersediaan sumber makanan yang berupa akar tanaman (Wallace, 1973). Nematoda parasit tumbuhan sebagian besar adalah anggota ordo Tylenchida dan Dorylaimida (Dropkin, 1980).

Nematoda kelompok lain yang peranannya sebagai saprofagus, pemakan cendawan, pemakan bakteri, dan predator kurang mendapat perhatian. Menurut van Noordwijk and Swift (1999) nematoda kelompok tersebut penting peranannya dalam perombakan bahan organik di dalam tanah. Nematoda perombak sebagian besar adalah ordo Rhabditida,

\footnotetext{
${ }^{1}$ Dosen Jurusan Proteksi Tanaman, Fakultas Pertanian, Universitas Lampung
} 
Dorylaimida, dan Mononchida (Yates, 1979 dalam Dindal, 1990)

Menurut Dropkin (1980), ekosistem yang sederhana (pertanian monokultur) menyebabkan penurunan keanekaragaman nematoda tetapi diikuti oleh peningkatan dominasi nematoda ordo Tylenchida yang sebagian besar berperan sebagai parasit tumbuhan. Sebaliknya ekosistem hutan memiliki jumlah jenis nematoda lebih tinggi tetapi persentase jenis nematoda ordo Tylenchida rendah.

Perubahan tipe vegetasi di atas permukaan tanah akan berpengaruh pada kuantitas dan kualitas akar serta bahan organik di dalam anah. Akar adalah sumber makanan kelompok nematoda parasit tumbuhan, sementara bahan organik akan mempengaruhi nematoda perombak. Penelitian ini dilakukan untuk mempelajari pengaruh perubahan hutan (hutan sekunder) menjadi tipe tata guna lahan lainnya (seperti wanatani, perkebunan, ladang ubi kayu, dan padang ilalang ) di Way Kanan terhadap keragaman dan total individu nematoda parasit dan nematoda nir-parasit tumbuhan di dalam tanah.

\section{BAHAN DAN METODE}

Penerokan nematoda dilakukan di ASB Bench-Mark Area Way Kanan $\left(4,22^{\circ}-4,31^{\circ}\right.$ LS dan $104,50^{\circ}$ - 105,40 ${ }^{\circ} \mathrm{BT}$ ) pada bulan November 1996 yaitu awal musim penghujan, dan bulan Desember 1997, yaitu pertengahan musim penghujan. Lima tipe tata guna lahan yang dipilih sebagai objek penerokan adalah hutan sekunder, wanatani (kebun buah campuran), perkebunan (kelapa sawit, sengon, dan karet), ladang ubikayu, dan padang ilalang. Pada tahun 1997 penerokan pada lahan perkebunan hanya diwakili kebun kelapa sawit muda.

Penerokan pada tahun 1996 dilakukan di 15 lokasi untuk lima tipe tata guna lahan. Pada areal setiap tipe tata guna lahan ditentukan satu situs seluas $40 \mathrm{~m} \times 5 \mathrm{~m}$. Pada setiap situs ditentukan secara sistematik tiga titik menurut arah diagonal situs. Pada titik-titik terok dilakukan penggalian sampai kejelukan $30 \mathrm{~cm}$ dan tanah kemudian dikomposit secara merata dan diambil sebanyak satu kilo gram untuk di esktraksi.
Penerokan pada tahun 1997 dilakukan di lima lokasi untuk 5 tipe tata guna lahan. Pada setiap tipe tata guna lahan ditentukan situs seluas $40 \mathrm{~m}$ x 5m dan pada situs tersebut ditentukan lima titik terok sepanjang transek situs. Pada setiap titik terok dilakukan penggalian sampai kejelukan $30 \mathrm{~cm}$. Sebanyak satu kilogram tanah diambil dari setiap titik terok untuk diekstraksi.

Ekstraksi-isolasi nematoda dari tanah dilakukan di Laboratorium Hama dan Penyakit Tumbuhan, Jurusan Proteksi Tanaman Fakultas Pertanian Universitas Lampung. Metode ekstraksi yang dipilih adalah metode dekantasi dan sentrifugasi menggunakan larutan gula (Dropkin, 1991). Ekstraksi dilakukan terhadap 100 cc tanah dari satu kilogram tanah terok. Nematoda hasil ekstraksi dimatikan dengan pemanasan sampai $50^{\circ} \mathrm{C}$ dan kemudian difiksasi menggunakan larutan FAA (Formalin Acetic Acid).

Penghitungan nematoda dilakukan di bawah mikroskop stereo binokuler pada perbesaran 40 kali. Preparat semipermanen dibuat untuk keperluan identifikasi. Identifikasi sampai tingkat ordo dan genus dilakukan pada perbesaran 100-400 kali dibawah mikroskop majemuk dengan menggunakan kunci determinasi nematoda parasitik tumbuhan bergambar (Mai \& Lyon, 1975) dan untuk nematoda nir-parasitik tumbuhan identifikasi sampai tingkat ordo menggunakan Dindal (1990).

\section{HASIL DAN PEMBAHASAN}

\section{Nematoda yang Terisolasi}

Nematoda yang terisolasi dari kelima tipe tata guna lahan dapat dikelompokkan menjadi empat ordo yaitu Tylenchida, Dorylaimida, Rhabditida, dan Mononchida. Sebelas genus merupakan anggota ordo Tylenchida dan dua genus tergolong ordo Dorylaimida. Ordo Rhabditida, Mononchida, dan sebagian Dorylaimida tidak dapat diidentifikasi sampai tingkat genus. Ordo dan genus nematoda dari kelima tipe tata guna lahan disajikan pada Tabel 1. 
Tabel 1. Ordo dan genus nematoda yang terekstraksi dari lima tipe tata guna lahan di Way Kanan tahun 1996 dan 1997

\begin{tabular}{|c|c|c|c|c|c|c|c|c|c|c|}
\hline \multirow{3}{*}{$\begin{array}{c}\text { Nama } \\
\text { Ordo / Genus }\end{array}$} & \multicolumn{10}{|c|}{ Tipe Tata Guna Lahan } \\
\hline & \multicolumn{2}{|c|}{$\begin{array}{l}\text { Hutan } \\
\text { sekunder } \\
\text { (tahun) }\end{array}$} & \multicolumn{2}{|c|}{$\begin{array}{l}\text { Wana- } \\
\text { tani } \\
\text { (tahun) }\end{array}$} & \multicolumn{2}{|c|}{$\begin{array}{l}\text { Perke- } \\
\text { bunan } \\
\text { (tahun) }\end{array}$} & \multicolumn{2}{|c|}{$\begin{array}{l}\text { Ubi- } \\
\text { kayu } \\
\text { (tahun) }\end{array}$} & \multicolumn{2}{|c|}{$\begin{array}{l}\text { Padang } \\
\text { ilalang } \\
\text { (tahun) }\end{array}$} \\
\hline & 96 & 97 & 96 & 97 & 96 & 97 & 96 & 97 & 96 & 97 \\
\hline Ordo : Rhabditida & + & + & + & + & 0 & + & + & + & + & + \\
\hline Ordo : Mononchida & 0 & 0 & 0 & 0 & 0 & + & + & 0 & 0 & + \\
\hline Ordo : Dorylaimida & + & + & + & + & + & + & + & + & + & + \\
\hline Xiphinema & 0 & 0 & 0 & 0 & 0 & + & 0 & 0 & 0 & + \\
\hline Longidorus & 0 & + & 0 & + & 0 & + & 0 & 0 & 0 & 0 \\
\hline \multicolumn{11}{|l|}{ Ordo : Tylenchida } \\
\hline Aphelenchus & 0 & + & 0 & + & 0 & + & 0 & + & 0 & + \\
\hline Criconemoides & + & + & + & + & + & + & + & + & + & + \\
\hline Dytilenchus & 0 & + & 0 & 0 & 0 & 0 & 0 & 0 & 0 & + \\
\hline Helicotylenchus & + & 0 & + & + & + & 0 & + & 0 & + & + \\
\hline Hemicycliophora & 0 & 0 & + & 0 & 0 & 0 & 0 & 0 & 0 & + \\
\hline Hoplolaimus & + & 0 & 0 & 0 & 0 & + & + & + & + & + \\
\hline Meloidogyne & + & + & 0 & + & + & + & + & + & + & + \\
\hline Pratylenchus & 0 & + & 0 & 0 & 0 & + & 0 & 0 & 0 & + \\
\hline Rotylenchus & + & 0 & + & + & + & + & + & 0 & + & + \\
\hline Scutellonema & 0 & 0 & 0 & 0 & 0 & 0 & 0 & 0 & + & 0 \\
\hline Tylenchus & + & + & + & 0 & + & + & + & + & + & + \\
\hline Total genus \& ordo & 8 & 9 & 7 & 8 & 6 & 12 & 9 & 7 & 9 & 14 \\
\hline
\end{tabular}

Keterangan: + = ditemukan nematoda, dan 0 = tidak ditemukan nematoda

Penerokan pada tahun 1996 menunjukkan bahwa ordo Rhabditida dan Dorylaimida terisolasi dari semua tipe tata guna lahan, kecuali pada lahan perkebunan tidak terisolasi ordo Rhabditida. Ordo Mononchida hanya terisolasi dari ladang ubikayu. Ordo Tylenchida terisolasi dari semua tipe tata guna lahan. Untuk ordo Tylenchida ini, dari hutan sekunder, padang ilalang, dan ladang ubikayu teridentifikasi masing-masing enam genus, sedangkan dari wanatani dan perkebunan masing-masing lima genus.

Penerokan pada tahun 1997 berhasil menemukan lebih banyak genus nematoda daripada tahun 1996. Pada tahun 1997 ini, ordo Rhabditida dan Dorylaimida terisolasi dari semua tipe tataguna lahan. Dua genus ordo Dorylaimida parasitik tumbuhan yang teridentifikasi adalah Longidorus dan
Xiphinema. Ordo Mononchida terisolasi dari padang ilalang. Nematoda parasit tumbuhan teridentifikasi sebanyak 11 genus dari lahan padang ilalang, sembilan genus dari perkebunan, tujuh genus dari lahan hutan sekunder, enam genus dari lahan wanatani, dan lima genus dari lahan ubi kayu.

Apabila dilihat dari jumlah genus khususnya parasit tumbuhan maka padang ilalang paling kaya di antara tata guna lahan yang disurvei. Sementara itu, lahan ubi kayu memiliki genus nematoda parasit tumbuhan yang paling sedikit. Dengan demikian, maka dapat diduga bahwa lahan padang ilalang mirip perkebunan dengan rumput alang-alang (Imperata cylindrica) sebagai tumbuhan utamanya. Rumput alang-alang dapat menjadi inang bagi banyak jenis nematoda. Walaupun padang ilalang dikenal sebagai 
lahan marginal, ternyata lahan tersebut dapat mendukung perkembangan dan pertumbuhan berbagai jenis nematoda parasit tumbuhan. Dukungan padang ilalang terhadap perkembangan dan pertumbuhan cacing tanah dan artropoda tanah dilaporkan juga oleh Hardiwinoto dan Prijono (1999). Mereka melaporkan bahwa jumlah cacing tanah dan artropoda pada padang ilalang paling tinggi diantara lahan yang menjadi objek survei yaitu hutan, wanatani, perkebunan, ubikayu, dan padang ilalang.

\section{Jumlah individu nematoda}

Pada Tabel 2 terlihat bahwa jumlah individu nematoda pada penerokan tahun 1996 lebih tinggi daripada jumlah individu pada penerokan tahun 1997, baik untuk nematoda parasit maupun nir-parasit tumbuhan. Jumlah individu nematoda nir-parasit tumbuhan pada tahun 1996 berkisar 24 - 51 individu per 300 cc tanah, sedangkan pada tahun 1997 berkisar 3 - 29 individu per 300 cc tanah. Nematoda parasit pada tahun 1996 berkisar 48 - 88 individu per 300 сc tanah, sedangkan pada tahun 1997 berkisar 12 - 60 individu per 300 cc tanah. Perbedaan jumlah ini mungkin berkaitan dengan kondisi iklim khususnya hujan ketika penerokan berlangsung. Penerokan tahun 1996 dilakukan pada awal musim penghujan, sedangkan penerokan tahun 1997 yaitu pertengahan musim penghujan. Menurut Wallace (1973), fluktuasi populasi nematoda di dalam tanah dipengaruhi oleh kelembaban dan aerasi tanah akibat curah hujan. Kelembaban tanah optimum bagi nematoda adalah kapasitas lapang (Wallace, 1971).

Tabel 2. Jumlah individu nematoda per 300 cc tanah pada lima tipe tata guna lahan di ASB Benchmark Area Way Kanan tahun 1996 dan 1997

\begin{tabular}{|c|c|c|c|c|c|c|}
\hline \multirow[b]{2}{*}{$\begin{array}{l}\text { Kelompok } \\
\text { Nematoda }\end{array}$} & \multirow[b]{2}{*}{ Statistik } & \multicolumn{5}{|c|}{ Tipe Tata Guna Lahan } \\
\hline & & $\begin{array}{l}\text { Hutan } \\
\text { sekunder }\end{array}$ & $\begin{array}{l}\text { Wana- } \\
\text { tani }\end{array}$ & $\begin{array}{l}\text { Perke- } \\
\text { bunan }\end{array}$ & $\begin{array}{l}\text { Ubi- } \\
\text { kayu }\end{array}$ & $\begin{array}{l}\text { Padang } \\
\text { ilalang }\end{array}$ \\
\hline & \multicolumn{6}{|c|}{ Tahun 1996} \\
\hline \multirow{2}{*}{$\begin{array}{l}\text { Nir- Parasit } \\
\text { Tumbuhan }\end{array}$} & $\bar{x}$ & 47,0 & 51,3 & 30,0 & 24,3 & 29,7 \\
\hline & $\begin{array}{l}\mathrm{S}_{\mathrm{E}} \\
\mathrm{F} \text { hit }=1,71 \mathrm{tn}\end{array}$ & 15,5 & 11,8 & 6,1 & 7,0 & 6,6 \\
\hline \multirow{3}{*}{$\begin{array}{l}\text { Parasit } \\
\text { Tumbuhan }\end{array}$} & $\bar{x}$ & 72,6 & 53,6 & 88,3 & 50,0 & 48,0 \\
\hline & $\begin{array}{l}\mathrm{S}_{\mathrm{E}} \\
\mathrm{F} \text { hit }=1,69 \mathrm{tn}\end{array}$ & 13,9 & 5,5 & 21,6 & 27,5 & 27,6 \\
\hline & \multicolumn{6}{|c|}{ Tahun 1997} \\
\hline \multirow{3}{*}{$\begin{array}{l}\text { Nir-Parasit } \\
\text { Tumbuhan }\end{array}$} & $\bar{x}$ & 28,8 & 27,2 & 2,6 & 4,0 & 6,6 \\
\hline & $\mathrm{S}_{\mathrm{E}}$ & 6,4 & 20,1 & 0,7 & 2,6 & 3,0 \\
\hline & F hit $=3,80^{*}$ & $\mathrm{a}$ & $a b$ & C & C & bc \\
\hline \multirow{3}{*}{$\begin{array}{l}\text { Parasit } \\
\text { Tumbuhan }\end{array}$} & $\bar{x}$ & 48,2 & 59,0 & 17,6 & 11,6 & 59,8 \\
\hline & $\mathrm{S}_{\mathrm{E}}$ & 7,6 & 23,8 & 3,0 & 9,7 & 4,8 \\
\hline & $\mathrm{F}$ hit $=2,9 *$ & $a b$ & $\mathrm{a}$ & $a b$ & $\mathrm{~b}$ & $\mathrm{a}$ \\
\hline
\end{tabular}

Keterangan : besaran nilai tengah ( $\overline{\mathrm{x}}$ ) dan galat baku $\left(\mathrm{S}_{\mathrm{E}}\right)$ dihitung dari data 3 ulangan (tahun 1996) dan 5 ulangan (tahun 1997), tn = tidak nyata, * = nyata ( uji F, $\alpha=0,05)$. Notasi dengan huruf sama dalam satu baris menunjukkan nilai tengah tidak berbeda (uji BNT, $\alpha=0,05$ ). Seluruh uji statistik dilakukan terhadap data yang ditransformasi $\sqrt{ } \mathrm{x}+1$. 
Tipe tata guna lahan mempengaruhi jumlah individu baik nematoda nir-parasit maupun nematoda parasit tumbuhan pada tahun 1997, namun tidak pada tahun 1996 (uji F 0,05).

Penerokan tahun 1997 menunjukkan bahwa jumlah individu nematoda nir-parasit tumbuhan paling tinggi pada lahan hutan sekunder $(28,8)$ dan tidak berbeda dengan lahan wana tani $(27,2)$. Jumlah individu nematoda ini rendah pada lahan perkebunan $(2,6)$ dan ubi kayu $(4,0)$. Pada lahan padang ilalang jumlah individu nematoda nir-parasit $(6,6)$ tidak berbeda dengan jumlah individu pada lahan wanatani, perkebunan dan ubi kayu.

Nematoda nir-parasit tumbuhan, di dalam jaring-jaring makanan berperan sebagai perombak bahan organik, pemakan cendawan, pemakan bakteri, dan predator. Hutan sekunder dan wanatani adalah tipe tata guna lahan dengan ekosistem yang memiliki vegetasi tumbuhan tahunan yang umur dan jenisnya beragam. Dibandingkan dengan tata guna lahan lainnya, hutan sekunder merupakan ekosistem yang kaya akan bahan organik (Hairiah, 1999). Ekosistem yang demikain ini sangat menguntungkan bagi perkembangan dan pertumbuhan nematoda nir-parasit tumbuhan.

Penerokan tahun 1997 menunjukkan bahwa jumlah individu nematoda parasit tumbuhan tidak menunjukkan pola perbedaan yang jelas pada kelima tipe tata guna lahan yang diterok. Total individu nematoda parasit tumbuhan pada lahan hutan sekunder $(48,2)$, wanatani $(59,0)$, perkebunan $(17,6)$, dan padang ilalang $(59,8)$ tidak berbeda menurut uji BNT $(0,05)$. Yang nyata menunjukkan perbedaan adalah antara wana tani dan padang ilalang dengan ubi kayu $(11,6)$.

Nematoda parasit tumbuhan sangat bergantung kepada akar tumbuhan sebagai sumber makanannya. Pada lahan wanatani terdapat berbagai jenis tumbuhan tahunan dengan tipe perakaran yang beragam pula. Selain itu, pada lahan ini juga tumbuh berbagai jenis gulma pada lantainya. Perakaran tumbuhan tahunan dan berbagai jenis gulma dapat dijadikan sumber makanan bagi nematoda parsit tumbuhan. Hal ini yang mendorong jumlah individu nematoda parasit pada lahan tersebut tinggi. Sebaliknya, jumlah individu pada ladang ubikayu rendah. Lantai ladang ubikayu bersih dari gulma karena sengaja dikendalikan. Hal ini yang menyebabkan massa akar yang ada pada lahan ubikayu rendah dan tidak dapat mendorong pertumbuhan dan perkembangan nematoda parasit tumbuhan. Alang-alang (Imperata cylindrica) yang dominan pada lahan padang ilalang memiliki sifat perakaran yang rapat. Sifat perakaran ini menguntungkan bagi nematoda parasit tumbuhan dan mendorong peningkatan populasi berbagai jenis nematoda parasit tumbuhan. Hal ini menyebabkan jumlah individu nematoda parasit pada lahan padang ilalang menjadi tinggi, tidak berbeda dengan jumlah individu nematoda ini pada lahan wanatani.

\section{SIMPULAN}

Nematoda ordo Rhabditida, Dorylaimida, dan Tylenchida terisolasi dari kelima tipe tata guna lahan. Jumlah genus nematoda parasit tumbuha pada lahan padang ilalang paling tinggi diantara keempat tata guna lahan lainnya. Jumlah individu nematoda parasit dan nir-parasit tumbuhan pada pada tahun 1996 antar tipe tata guna lahan tidak berbeda. Survei 1997 menunjukkan bahwa jumlah individu nematoda nirparasit tumbuhan pada hutan sekunder $(28,0 / 300 \mathrm{cc}$ tanah) lebih tinggi daripada lahan perkebunan (2,6/300 cc tanah), lahan ubi kayu (4,0/300 cc tanah), dan padang ilalang $(6,6 / 300$ cc tanah) tetapi tidak berbeda dengan wanatani (27,2/300 cc tanah). Jumlah individu nematoda parasit tumbuhan pada padang ilalang (59,8 /300 cc tanah), wanatani (59,0/300 cc tanah), hutan sekunder (48,2 /300 cc tanah), dan perkebunan (17,6 / 300 cc tanah) tidak berbeda nyata, tetapi jumlah individu nematoda ini pada padang ilalang dan wanatani nyata lebih tinggi daripada jumlah individu pada lahan ubi kayu (11,6/300 сc tanah).

\section{SANWACANA}

Penelitian ini merupakan bagian dari penelitian ASB Departemen Pertanian yang dilaksanakan oleh Tim ASB Unila termasuk penulis. Penulis mengucapkan terima kasih kepada ketua tim (Dr. F.X. Susilo) dan anggota lainnya (Prof. Dr. Muhajir Utomo serta Dra. Sri Murwani, M.Sc.) atas ijin penggunaan data dalam penerbitan ini. Ucapan terima kasih juga disampaikan kepada Ir. Pratiknyo, M.S. (kepala stasiun BMSF Bunga Mayang) beserta stafnya yang telah membantu kegiatan survei. Penulis juga mengucapkan terima kasih kepada saudara Putut Setia Iswara, SP dan Nusiati Asih, SP yang membantu dalam pengumpulan 
data. Kelancaran ekstraksi dan isolasi nematoda di laboratorium dibantu oleh saudara Suhaimi, Paryadi, dan Giwantoro. Untuk itu diucapkan terima kasih.

\section{DAFTAR PUSTAKA}

Dindal, D.L. 1990. Soil Biology Guide. John Wiley \& Sons, New York.

Dropkin, V.H. 1980. Introduction to Plant Nematology. John Wiley \& Sons, New York.

Giller, K.E., M.H. Bearse, P. Lavelle, A.M.N. Izac, \& M.J. Swift. 1997. Agricultural intensification, soil biodiversity, and agroecosystem function. Appl. Soil Ecology 6: 3-16.

Hairiah, K. 1999. Decomposition process and activity of soil engineer when forests are converted into agricultural use. Pages 53-61 in: Gafur, A., F.X. Susilo, M. Utomo, \& M. van Noordwijk, eds. Proceedings of Workshop Management of Agrobiodiversity in Indonesia for Sustainable Land Use and Global Environmental Benefits. ASB Report No. 9. Agency for Agricultural Research and Development Ministry of Agriculture and University of Lampung, Bogor, August 19—20, 1999.

Hardiwinoto, S. \& J. Prijono. 1999. Diversity, population, and biomass of soil macrofauna in several land use system in Jambi, central part of Sumatra. Pages 29-34 in: Gafur, A., F.X. Susilo, M. Utomo, \& M. van Noordwijk, eds. Proceedings of Workshop Management of Agrobiodiversity in Indonesia for
Sustainable Land Use and Global Environmental Benefits. ASB Report No. 9. Agency for Agricultural Research and Development Ministry of Agriculture and University of Lampung, Bogor, August 19-20, 1999

Mai, W.F. \& H.H. Lyon. 1975. Pictorial key to genera of plant parasitic nematodes. Cornell University Press. Ithaca and London.

Swift, M.J. \& J.M. Anderson. 1994. Biodiversity and ecosystem function in agricultural system. Pages 1538 in: Schulze, E.D. and H.A. Moony, eds. Biodiversity and Ecosystem Function. SpringerVerlag, Berlin.

Van Noordwijk, M. \& M.J. Swift. 1999. Belowground biodiversity and sustainability of complex agroecosystems. Pages 8-27 in: Gafur, A., F.X. Susilo, M. Utomo, \& M. van Noordwijk, eds. Proceedings of Workshop Management of Agrobiodiversity in Indonesia for Sustainable Land Use and Global Environmental Benefits. ASB Report No. 9. Agency for Agricultural Research and Development Ministry of Agriculture and University of Lampung, Bogor, August 19—20, 1999

Wallace, H.R. 1971. Abiotic influences in the soil environment. Pages 257-278 in: Zuckerman, B.M. W.F. Mai, and R.A. Rohde, eds. Plant parasitic nematodes : Morphology, Anatomy, Taxonomy, and Ecology. Academic Press, New York .

Wallace, H.R. 1973. Nematode Ecology and Plant Diseases. Edward Arnold, London. 
I Gede Swibawa: Keanekaragaman nematoda tanah pada berbagai tipe tataguna lahan di ASB-Benchmark area Way Kanan 